\title{
Influences of artificial root exudate components on the behaviors of BDE-28 and BDE-47 in soils: desorption, availability, and biodegradation
}

\author{
Honglin Huang ${ }^{1} \cdot$ Sen Wang ${ }^{1,2} \cdot$ Jitao $^{\mathrm{Lv}^{1}} \cdot{\mathrm{Xuehui} \mathrm{Xu}^{1} \cdot \text { Shuzhen Zhang }}^{1}$
}

Received: 4 August 2015 / Accepted: 28 December 2015 /Published online: 8 January 2016

(C) Springer-Verlag Berlin Heidelberg 2016

\begin{abstract}
Behaviors of BDE-28 and BDE-47 in two distinct soils (Phaeozem and Acrisol) as affected by the separate addition of root exudate components (i.e., oxalic acid, glycine, and fructose) were investigated by a soil microcosm incubation experiment. The results showed that root exudate components promoted the desorption of BDE-28 (57.6-235.0\%) and BDE-47 (56.9-223.7\%) from the soils due to the enhancement of their water solubilities. The addition of root exudate components increased the $n$-butanol extractability of BDE-28 and BDE-47 by $20.3-72.5$ and 48.6-169.2 \%, respectively, which had a positive correlation with the concentrations of dissolved organic carbon (DOC) in the soils $(p<0.01)$, suggesting that the increase of DOC in the soils by root exudate components was the major factor to enhance the extractability. Fructose and oxalic acid promoted the desorption and increased the availability of BDE-28 and BDE47 in the soils more efficiently than glycine. The addition of different root exudate components resulted in distinct shifts in soil microbial community structure $(p<0.05)$. Oxalic acid caused the greatest impacts on the soil bacterial communities
\end{abstract}

Responsible editor: Zhihong Xu

Electronic supplementary material The online version of this article (doi:10.1007/s11356-015-6025-y) contains supplementary material, which is available to authorized users.

Shuzhen Zhang

szzhang@rcees.ac.cn

1 State Key Laboratory of Environmental Chemistry and Ecotoxicology, Research Center for Eco-Environmental Sciences, Chinese Academy of Sciences, P. O. Box 2871, Beijing 100085, China

2 Department of Environmental Sciences, College of Urban and Environmental Sciences, Northwest University, Xi'an 710027, China and increased the degradation rates of BDE- 28 and BDE-47 most obviously. The findings of this study clarified the roles of root exudate components in affecting the behaviors of polybrominated diphenyl ethers (PBDEs) in soils.

Keywords BDE-28 and BDE-47 · Soil · Root exudate component $\cdot$ Desorption $\cdot$ Availability $\cdot$ Biodegradation

\section{Introduction}

Soils are an important sink for organic contaminants in the environment. The behaviors of organic contaminants in soils are generally governed by their complex physical, chemical, and biological processes such as sorption-desorption, biodegradation, and uptake by organisms (Hayat et al. 2010). Sorption and desorption of organic contaminants are fundamental processes controlling their transportation in soils (Tolls 2001). The uptake of organic contaminants was determined by their bioavailability and biotransformation in soils, which have been addressed as the key processes affecting their toxicity to and accumulation in biota (Cui et al. 2013; Semple et al. 2003). These diverse processes coexist for organic contaminants in soils and influence each other; therefore, a thorough investigation of these processes is necessary in order to comprehensively understand the unique behaviors of organic contaminants in soils.

Biological activity, especially root exudation, has been demonstrated to significantly affect the behaviors of organic contaminants in soils (Luo et al. 2006; Zhu et al. 2009; Balseiro-Romero et al. 2014; Martin et al. 2014; He et al. 2015). Some studies have evidenced the effects of root exudates on the desorption and availability of organic contaminants in soils. For instance, Gao et al. (2010a) have found that root exudates markedly influence the desorption of 
phenanthrene and pyrene in soils, and the desorption increased with increasing root exudate concentration. White et al. (2006) have observed that the addition of root exudates significantly increases the availability of the weathered polychlorobiphenyls (PCBs) in soils to plants and earthworms. Root exudates are likely to stimulate soil microbial diversity and activity and thereby facilitate microbial biodegradation of organic contaminants. Both in vivo and in vitro experiments have demonstrated that root exudates can enhance microbial biodegradation of petroleum hydrocarbons in soils (Miya and Firestone 2001; Joner et al. 2002; Corgié et al. 2004, 2006). Research by Yoshitomi and Shann (2001) has shown that root exudates stimulate microbial mineralization of polycyclic aromatic hydrocarbons (PAHs) by the growth of soil microorganisms and the changes in structure and function of microbial community. Nevertheless, most of these available studies which investigated the effects of root exudates on the behaviors of organic contaminants in soils have only focused on the functions of the whole mixed exudates. Root exudates contain a rather complex mixture of components, which mainly include sugars, amino acids, and organic acids (Farrar et al. 2003; Bais et al. 2006). Accordingly, it has been hypothesized that these components may play different roles in affecting the behaviors of organic contaminants in soils. However, by far, little work is available to comparably investigate the effects of different root exudate components on the processes of organic contaminants in soils. No attempt has been made in any of these studies to identify the role of individual components in root exudates in biodegradation of organic contaminants in soils.

Polybrominated diphenyl ethers (PBDEs) are ubiquitous in the environment due to their wide use as flame retardants, and high levels of PBDEs in soils have been reported (Wong et al. 2007; Sellström et al. 2005; Wang et al. 2014). Another important fact is that PBDEs are being phased out of use in many countries in recent years, and thus, soils may become an important secondary emission source of PBDEs to the environment (Li et al. 2010). Therefore, it is important to elucidate the desorption and availability of PBDEs in soils, particularly under the influences of biological activity such as root exudation. On the other hand, PBDEs can be broken down into lower brominated congeners by soil microorganisms (Lee and He 2010; Wong et al. 2012) and bring additional adverse influences to bear on the environment and human health due to their different biological effects compared with their precursor PBDEs. However, it still remains unclear whether the enhanced degradation rate of PBDEs by microbial activities is associated with the effects of root exudates and how root exudate components act on the biodegradation of PBDEs in soils.

In this study, a microcosm incubation experiment was conducted to investigate the behaviors of PBDEs in a black soil (Phaeozem) and a red soil (Acrisol) as affected by the separate addition of oxalic acid, glycine, and fructose as the representatives of the dominant components of root exudates. The PBDE congeners of BDE-28 and BDE- 47 were selected as the target contaminants considering their extensive occurrence in the PBDE-contaminated soils. The aim of this study was to determine whether and how root exudate components influence the desorption, availability, and biotransformation of BDE-28 and BDE-47 in soils.

\section{Materials and methods}

\section{Chemicals and reagents}

Solid standards of BDE-28 and BDE-47 were purchased from AccuStandard (AccuStandard, New Haven, USA). Surrogate standards of BDE-77 and ${ }^{13} \mathrm{C}-\mathrm{PCB}-141$ were purchased from Wellington Laboratories, Inc., Guelph, Ontario, Canada. Standard solution containing 19 PBDE congeners (mono- through tetra-BDEs) was purchased from AccuStandard, New Haven, USA. All solvents used, i.e., dichloromethane (DCM), hexane, and acetone, were of HPLC grade and purchased from Fisher Scientific (Fair Lawn, NJ, USA). Ultrapure water (18.2 M $\Omega$ ) used was obtained by using a Milli-Q system (Milli-Q Advantage A10, Millipore Corporation, Billerica, MA, USA). Oxalic acid, glycine, and fructose (all A.G.) were obtained from Sinopharm Chemical Reagent Co., Ltd (Beijing, China).

\section{Soils and closed-bottle moist microcosm}

PBDEs always exist as a mixture in field soils, which brings difficulties in distinguishing the debrominated products from the same PBDE congeners that originally existed in the soils. Therefore, soils artificially contaminated with BDE- 28 and BDE-47 were used in this study. A red soil (Phaeozem) and a black soil (Acrisol), free of PBDEs, were collected from the 5-20-cm-depth zone of agricultural fields in Jiangxi and Heilongjiang provinces, China, respectively. The two soils were distinct with respect to their organic carbon contents and $\mathrm{pH}$ levels. Their basic properties are listed in Table 1. Soil samples were air-dried and sieved $(0.5 \mathrm{~mm})$. BDE-28 and BDE-47 dissolved in acetone were spiked into the soils. After the acetone evaporated, spiked soil was then continuously tumbled with non-spiked soil for $2 \mathrm{~h}$ at room temperature to ensure efficient mixing and to bring the soil to a final concentration of $200 \mathrm{ng} / \mathrm{g}$ of BDE-28 or BDE-47, which was chosen according to their general contamination levels in soils. The spiked soils were then allowed to dry in a fume hood in the dark until the acetone had volatilized completely, shaken for $0.5 \mathrm{~h}$ every day, and homogenized. Twenty grams of the spiked soils was then packed into a custom brown glass vial $(50 \mathrm{~mL})$. The oxalic acid, glycine, and fructose as root exudate components 
Table 1 Selected properties of the two test soils

\begin{tabular}{llllllll}
\hline Soil & Location & SOM (\%) & $\mathrm{pH}$ & $\mathrm{Fe}$ Ox $(\mathrm{mg} / \mathrm{kg})$ & & \multicolumn{2}{l}{ Soil texture } \\
\cline { 5 - 7 } & & & & & Clay (\%) & Silt (\%) & Sand (\%) \\
\hline Red soil & Jiangxi & 0.45 & 4.12 & 349 & 34.2 & 54.1 & 11.7 \\
Black soil & Harbin & 6.15 & 7.02 & 2705 & 43.4 & 25.5 & 31.1 \\
\hline
\end{tabular}

were added separately into the soils at a concentration of $20 \mathrm{~g} / \mathrm{kg}$, similar to those used by Joner et al. (2002) and Gao et al. (2010a), and then mixed. Soils were rinsed with deionized water every day to maintain $50 \%$ of field capacity by weighing and incubated at $25{ }^{\circ} \mathrm{C}$ in the dark for 60 days. Control soils free of root exudate component were included. Three replicates were set for each treatment.

\section{Desorption of BDE-28 and BDE-47 as affected by root exudate components}

Approximately $2 \mathrm{~g}$ of the soils spiked with BDE-28 or BDE-47 after being aged for 60 days was weighed and placed into 40$\mathrm{mL}$ glass centrifuge tubes together with $25 \mathrm{~mL}$ of solution of each of the root exudate components $(0-60.0 \mathrm{~g} / \mathrm{L})$ containing $0.05 \% \mathrm{NaN}_{3}$ to inhibit microbial activities according to the method by Gao et al. (2010a) with minor modifications. The tubes were shaken in the dark at $200 \mathrm{rpm}$ on a gyratory shaker and sampled at different time intervals within 6 days, which has been shown long enough to achieve an apparent equilibrium desorption for both BDE-28 and BDE-47 (data not shown). Then, the vials were removed from the rotator and centrifuged at $3000 \mathrm{rpm}$ for $15 \mathrm{~min}$. The supernatant was taken out and the soil left in the tube was freeze-dried. BDE-28 and BDE-47 in the soils and supernatants were extracted and analyzed according to the method described in the Supplementary material. Soil water partitioning coefficients $\left(K_{\mathrm{d}}, \mathrm{L} / \mathrm{kg}\right)$ for BDE-28 and BDE-47 were calculated $\left(K_{\mathrm{d}}=C_{\text {soil }} / C_{\text {water }}\right)$. Losses caused by photochemical decomposition, volatilization, and sorption to tubes were found to be negligible. All equilibrium concentrations of BDE-28 and BDE-47 in the solutions were below their aqueous solubility.

\section{Solubilities of BDE-28 and BDE-47 in root exudate components}

Batch experiments were conducted in duplicate to determine the solubilities of BDE-28 and BDE-47 in each of the root exudate components. Four microliters of root exudate component solution at a series of concentrations $(0,0.1,1.0,10.0$, 20.0, 40.0, and $60.0 \mathrm{~g} / \mathrm{L}$ ) containing $50 \mathrm{mM} \mathrm{NaN}_{3}$ as a biocide and four baked glass beads of about $3 \mathrm{~mm}$ in diameter aiding for mixing were placed in 10-mL Corex centrifuge tubes with Teflon-lined screw caps. Excess mass of solid BDE-28 or BDE-47 was added into each tube for dissolution. BDE-28 or BDE-47 dissolved in Milli-Q water was set as a reference value, and the root exudate component solution was set as a control. The samples were equilibrated on a reciprocating shaker for 7 days at $25{ }^{\circ} \mathrm{C}$ and subsequently centrifuged at $4500 \mathrm{rpm}$ for $30 \mathrm{~min}$ to completely separate the undissolved solutes. An appropriate aliquot of the supernatant was then carefully withdrawn with a volumetric pipette. BDE-28 and BDE-47 in the aqueous phase were extracted and analyzed using the method described in the Supplementary material.

\section{Extractable BDE-28 and BDE-47 and organic carbon in the soils as affected by root exudate components}

Two grams of soil was taken from each treatment and added together with $10 \mathrm{~mL}$ of $100 \% n$-butanol into a $35-\mathrm{mL}$ glass centrifuge tube, and then screwed with the tube cap tightly. The samples were sonicated in an ultrasonic bath for $60 \mathrm{~min}$ at $25{ }^{\circ} \mathrm{C}$. Three replicates were prepared. Soil and solvent were separated by centrifugation at $3000 \mathrm{rpm}$ for $15 \mathrm{~min}$. Four microliters of supernatant was collected and filtered through a $0.22-\mu \mathrm{m}$ filter for the analysis of BDE-28 and BDE-47.

In order to assess if the addition of root exudate components influenced the soil carbon content, the content of dissolved organic carbon (DOC) in the soils after treatment with root exudate components was determined. Twenty-five microliters of ultrapure water containing $0.05 \% \mathrm{NaN}_{3}$ was mixed with $5.0 \mathrm{~g}$ of aged soil in a $30-\mathrm{mL}$ glass centrifuge tube. The tubes were shaken in the dark at $200 \mathrm{rpm}$ on a gyratory shaker for $24 \mathrm{~h}$ to achieve equilibration. Then, the samples were centrifuged at $3000 \mathrm{rpm}$ for $15 \mathrm{~min}$. An aliquot of supernatant was removed, and the DOC concentration was measured using a TOC Analyzer (Phoenix 8000, Tekmar-Dohrmann Co., USA).

\section{Soil bacterial communities}

Effects of root exudate components on soil bacterial communities were evaluated based on PCR-DGGE profiles. The soils after the addition of root exudate components and incubation for 60 days were thoroughly homogenized and frozen at $-80{ }^{\circ} \mathrm{C}$ prior to DNA extraction. Total DNA was extracted from $300 \mathrm{mg}$ of fresh soil samples in a closed microcosm with the Power Soil DNA Isolation kit (Catalog \# 12855-50, Mo Bio Laboratories Inc., CA). Quality and integrity of soil DNA were checked by electrophoresis on $1 \%$ agarose gels. DNA 
was quantified using a NanoDrop 2000 spectrophotometer (Thermo Fisher Scientific, USA). Three replicates were used for DNA evaluation. Veriti fast 96-Well Thermal Cycler (Applied Biosystems, USA) was used in PCR amplification. The variable $\mathrm{V} 3$ region of the $16 \mathrm{~S}$ rRNA gene was amplified using the universal bacterial primers of F357-GC (5-GC-clampGCC TAC GGA GGC AGC AG-3) and 518R (5-ATT ACC GCG GCT GCT GG-3) to yield a 220-base-pair fragment (Fig. S1). The PCRs were carried out in a total volume of $50 \mu \mathrm{L}$ with $45 \mu \mathrm{L}$ PCR SuperMix (Life Technologies, USA), $1 \mu \mathrm{L}$ of $\mathrm{V} 3$ primers ( $20 \mu \mathrm{M}$ of each primer), and $1 \mu \mathrm{L}$ of template DNA. The $16 \mathrm{~S}$ rDNA was amplified as follows: $94{ }^{\circ} \mathrm{C}$ for $10 \mathrm{~min}$, followed by 30 cycles of $94{ }^{\circ} \mathrm{C}$ for $1 \mathrm{~min}, 55^{\circ} \mathrm{C}$ for $1 \mathrm{~min}$, and $72^{\circ} \mathrm{C}$ for $30 \mathrm{~s}$, and with a final extension at $72{ }^{\circ} \mathrm{C}$ for $10 \mathrm{~min}$, followed by cooling at $4{ }^{\circ} \mathrm{C}$. The PCR products were confirmed by using $1 \%(w / v)$ agarose gel electrophoresis and SYBR ${ }^{\circledR}$ Gold staining. Extracted soil microbial DNA sizes were all less than $10 \mathrm{~kb}$.

DGGE analysis was performed with a D-Code universal mutation detection system (Bio-Rad, USA). Samples of $20 \mu \mathrm{L}$ of PCR products were loaded onto $10 \%(w / v)$ polyacrylamide gel containing 40-60\% denaturing gradient of formamide and urea. The electrophoresis was run at $60^{\circ} \mathrm{C}$ in $1 \times \mathrm{TAE}$ for $16 \mathrm{~h}$ at a constant voltage of $65 \mathrm{~V}$. After the electrophoresis, the polyacrylamide gel was stained with SYBR Green I nucleic acid gel stains and visualized on a fluorescent and visible light gel imaging system (AlphaImager Mini, USA). The gel was photographed with a CCD camera.

\section{Degradation of BDE-28 and BDE-47 in the soils}

Degradation of BDE-28 and BDE-47 in the soils with the addition of root exudate components in closed-bottle moist microcosms was monitored at intervals of 1, 5, 15, 30, 45, and 60 days. Two grams (dry weight) of soil samples was spiked with $30 \mathrm{ng}$ of the surrogate of ${ }^{13} \mathrm{C}$-PCB-141. Standard solution containing 19 PBDE congeners (mono- through tetraBDEs) was used to identify the debrominated products of BDE-28 and BDE-47. The extraction and analysis procedures for PBDEs were described in our previous publication (Huang et al. 2011), and the details are provided in the Supplementary material. An Agilent 7890 GC-MS (5975 inert) (Agilent, Palo Alto, CA, USA) and a DB-5MS column $(30 \mathrm{~m} \times 0.32 \mathrm{~mm} \times 0.25 \mu \mathrm{m})(\mathrm{J} \& \mathrm{~W}$ Scientific, Folsom, CA) were used for the analysis. Quality assurance and quality control of the extraction and analysis are provided in the Supplementary material.

\section{Data analysis}

The data were subjected to statistical analysis by using the SPSS version 12.0 software package. Analysis of variance (ANOVA) and Duncan's multiple range test were used to examine the significance of desorption, extractability, and biodegradation of BDE-28 and BDE-47 in the soils as affected by root exudate components. OriginPro 8.0 was used to fit the desorption of BDE-28 and BDE-47 as a function of root exudate component concentrations and their degradation kinetics with incubation time. The DGGE profiles were analyzed by unweighted pair-group method using arithmetic averages (UPGMA), and the similarity was calculated by coefficient of DICE using the Quantity One software (Bio-Rad, USA). The Shannon-Weaver index was used to estimate phylotype diversity.

\section{Results}

\section{Desorption of BDE-28 and BDE-47 as affected by root exudate components}

Desorption of BDE-28 and BDE-47 as a function of concentrations of root exudate components $(0-60 \mathrm{~g} / \mathrm{L})$ is presented in Fig. 1. The presence of root exudate components significantly enhanced the release of BDE-28 and BDE-47 from the soils. The amount of the desorbed PBDEs from the soils increased with increasing concentrations of the root exudate components. For example, the desorption amounts of BDE-28 and BDE-47 in the red soil increased from 3.3 to 9.8 and 0.9 to $3.1 \mu \mathrm{g} / \mathrm{kg}$, respectively, when oxalic acid concentration increased from 0 to $60 \mathrm{~g} / \mathrm{L}$. A similar tendency was observed for the black soil. Desorption of BDE-28 and BDE-47 increased rapidly at first and then slowly with the increase of the concentrations of root exudate components. The experimental data fitted well with the second order of exponential model, and the correlation coefficients $R^{2}$ were 0.9638 0.9997 and 0.9225-0.9997, respectively, for BDE-28 and BDE-47 in the soils. The enhanced desorption of BDE-28 and BDE-47 from the soils varied obviously among the root exudate components, following the order fructose $\approx$ oxalic acid $>$ glycine treatments, indicating that fructose and oxalic acid promoted the desorption of the BDE-28 and BDE-47 from the soils more strongly than glycine. Irrespective of the root exudate components added, the desorption amounts of BDE-28 and BDE-47 were always less in the black soil than in the red soil which had a relatively lower soil organic matter content, and the amount of BDE-28 desorbed was higher than BDE-47 in both the red and black soils.

\section{Extractable PBDEs in the soils with the addition of root exudate components}

Concentrations of the extractable BDE-28 and BDE-47 in the soils with the addition of root exudate components were significantly higher than those in the control soils $(p<0.05)$, which indicates that all of the three root exudate components enhanced 
Fig. 1 Desorption of BDE-28 and BDE-47 from the soils as a function of the concentrations $(0-60 \mathrm{~g} / \mathrm{kg})$ of the root exudate components. The experimental data fitted well with the second order of exponential model. Data were the results of experiments performed in triplicate, and error bars represent the standard deviation
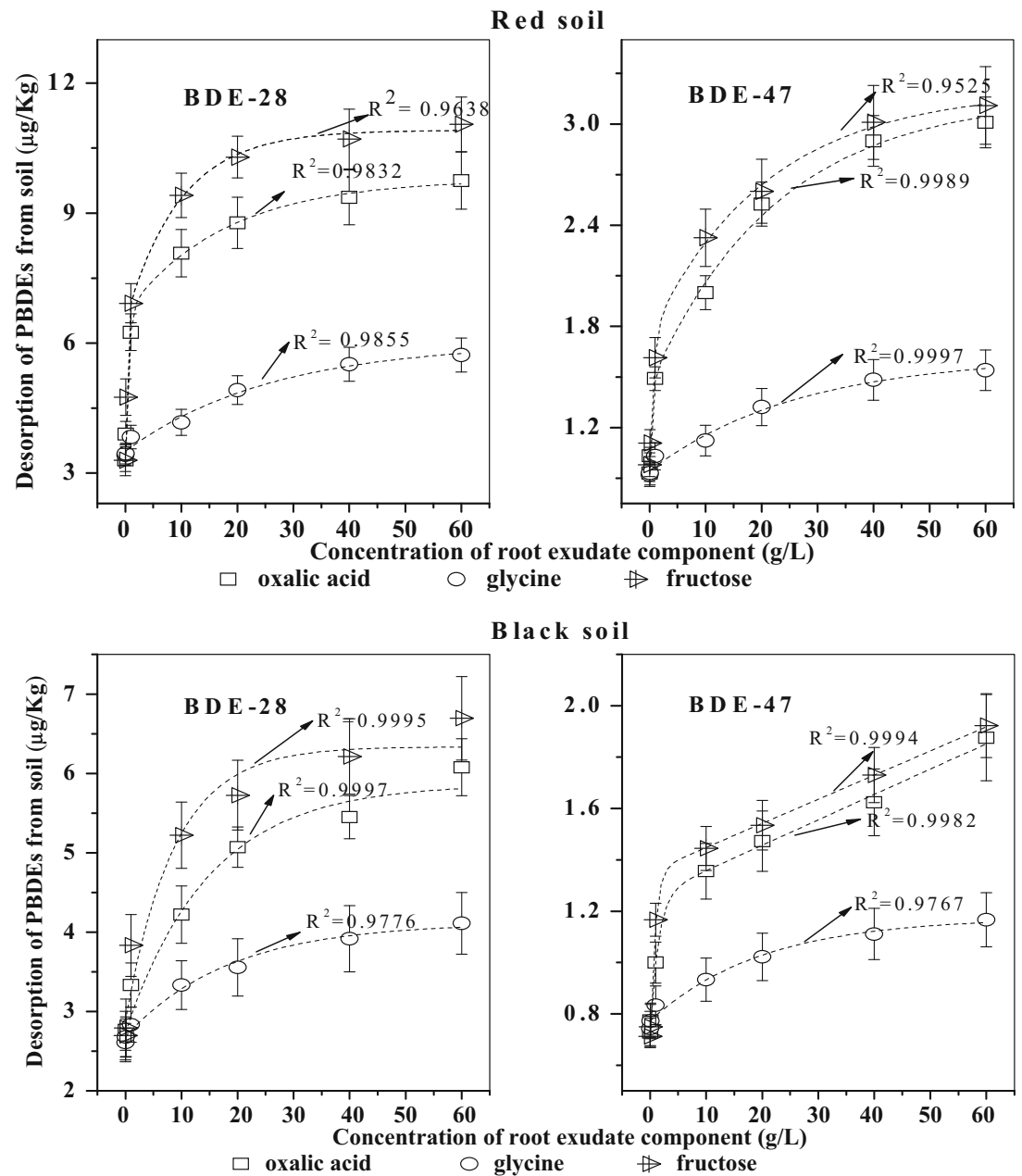

the extractabilities of BDE-28 and BDE-47 in the soils. However, the degrees of extractabilities of BDE-28 and BDE-47 differed among the root exudate components, following the order of oxalic acid $>$ fructose $>$ glycine (Fig. 2). Concentrations of $n$-butanol-extractable BDE-28 and BDE-47 in the red soil with the treatment of the same root exudate component were slightly but not significantly higher than those in the black soil. In comparison, the extractable concentration of BDE-28 was higher than that of BDE-47 in both the red soil and the black soil.

\section{Changes in soil bacterial community affected with root exudate components}

The addition of root exudate components significantly increased the total amount of soil microbial DNA (Table 2). Different root exudate components promoted microbial growth at different degrees, and the highest DNA content was found in the soils with the addition of oxalic acid. The addition of BDE-28 and BDE-47 reduced the amount of DNA extracted from the soils. Root exudate components induced significant modifications of soil microbial community as shown in the DGGE band profiles (Fig. 3, $p<0.05)$. The DGGE profile for each consortium yielded between 17 and 34 bands, and the addition of root exudate components increased the number of detectable bands in the soils. Some of the bands that appeared in the treatments with the addition of the root exudate components such as bands A1-A12 for the red soil and bands B1-B14 for the black soil were more intense or distinct than those of the controls. The diversity indexes of Shannon-Weaver index were increased by the addition of root exudate components but decreased in the present of BDE-28 and especially of BDE 47 in the soils (Fig. S2a). Cluster analysis indicated that the soil microbial community profiles for the treatments with root exudate components were clustered into the same clade and less similar to the controls with the similarity coefficients ranging from 0.56 to 0.73 (Fig. S2b).

\section{Biodegradation of BDE-28 and BDE-47 in the soils}

Time-dependent biodegradation of BDE-28 and BDE-47 exhibited similar trends for all the treatments, with a fast initial dissipation phase followed by a relatively slow disappearance (Fig. 4). Root exudate components enhanced the degradation rates of BDE-28 and BDE-47 in both the red and the black soils. Taking BDE-28 in the red soil as an example, the 
Fig. $2 n$-Butanol-extractable PBDEs in the soils with the addition of $20 \mathrm{~g} / \mathrm{kg}$ root exudate component and aging for 60 days Error bars represent standard errors. Means $(n=3)$ with the same letter are not significantly different at the $5 \%$ level
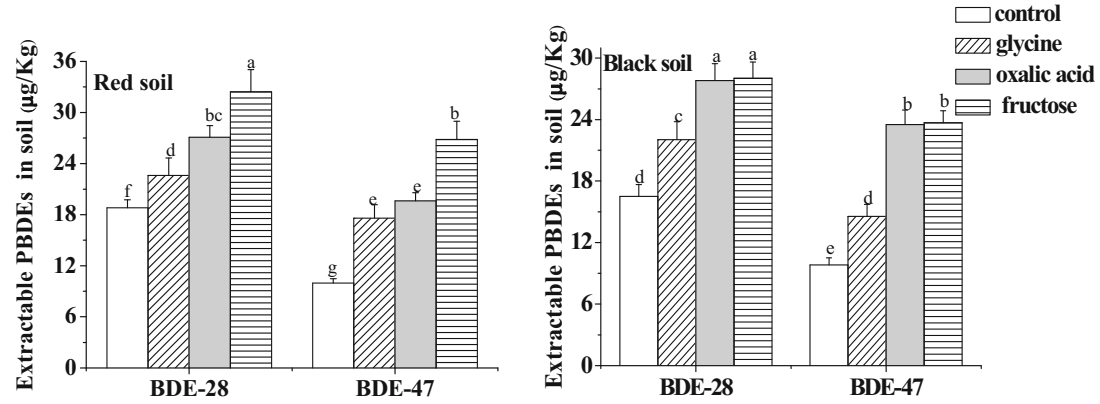

maximal degradation extents in the soils incubated for 60 days with the addition of oxalic acid, glycine, and fructose were $12.3,8.01$, and $10.9 \%$ higher than those of the control, respectively $(p<0.05)$. Biodegradation of BDE-28 or BDE-47 in the soils was well described by the first-order kinetics (Table S1 in the Supplementary material). The biodegradation rate constants of BDE-28 and BDE-47 followed the order of oxalic acid $>$ fructose $>$ glycine treatments $>$ controls, indicating that the presence of oxalic acid produced their biodegradation in the soils most obviously. Debrominated products of BDE-47 and BDE-28 in the soils ranging from mono- to tri-BDEs were generated within 60 days (Fig. S3). Further detailed analysis showed that the addition of root exudate components to the soils significantly increased the numbers and concentrations of the debrominated products of BDE-28 and BDE-47.

\section{Discussion}

It was evidenced in this study that fructose and oxalic acid promoted the desorption of BDE-28 and BDE-47 from the soils more efficiently than glycine. Gao et al. (2010b) and Sun et al. (2012) also found that the effects of root exudates on the desorption of phenanthrene and pyrene from soils were dominantly due to the involvement of organic acids. Root exudate components are capable of increasing water solubilities of some organic contaminants, leading to their release from soils (Bais et al. 2006). The apparent enhanced solubilities of both BDE-28 and BDE-47 in aqueous phase were evidenced in this study (Fig. 5), suggesting that root exudate components acted as co-solvents to increase the solubilities of BDE-28 and BDE-47 in the soils. Furthermore, solubilities of BDE-28 and BDE-47 shared the same tendency with their enhanced desorption when the concentrations of root exudate components increased. Consistently, the soil water partitioning coefficients $\left(K_{\mathrm{d}}, \mathrm{L} / \mathrm{kg}\right)$ for BDE-28 and BDE47 were significantly lower in the presence of root exudate components than those of the controls $(p<0.05)$ (Fig. S4). The enhanced extent of BDE-28 solubility by root exudate components was higher than that of BDE-47. For example, the $S_{\mathrm{w}}$ values of BDE-28 and BDE-47 in $60 \mathrm{~g} / \mathrm{L}$ oxalic acid solution were 2.5 and 1.9 times higher than the corresponding $S_{\mathrm{w}}$ values in water.

$n$-Butanol has been used as an appropriate extraction solvent to determine the availability of organic contaminants in soils (Cui et al. 2013; Liste and Alexander 2002; Kelsey et al. 1997). Enhanced availability of some organic contaminants including PAHs and PCBs in soils by root exudates have been reported (White et al. 2003, 2006; Luo et al. 2006), which were consistent with the observations of this study. After their addition to soils, root exudate components would be included in the soil DOC. Furthermore, root exudate components in
Table 2 DNA concentrations in soils as affected by the application of root exudate components. Data are presented as mean \pm SEM of experiments performed in triplicate

\begin{tabular}{llllrr}
\hline DNA content $(\mu \mathrm{g} / \mathrm{g}$ dry soil) & Contaminant & Control & Oxalic acid & \multicolumn{1}{l}{ Glycine } & \multicolumn{1}{l}{ Fructose } \\
\hline Red soil & BDE-28 & $1.55 \pm 0.14$ & $3.50 \pm 0.28$ & $1.69 \pm 0.10$ & $3.01 \pm 0.37$ \\
& BDE-47 & $1.32 \pm 0.12$ & $2.94 \pm 0.25$ & $1.96 \pm 0.15$ & $2.99 \pm 0.23$ \\
Black soil & BDE-28 & $9.11 \pm 0.85$ & $25.99 \pm 2.08$ & $14.94 \pm 1.12$ & $13.84 \pm 1.52$ \\
& BDE-47 & $9.11 \pm 0.82$ & $28.53 \pm 2.28$ & $16.51 \pm 1.25$ & $19.17 \pm 2.10$ \\
& & & & & \\
Significance ${ }^{a}$ due to & & $* * *$ & \\
$\quad$ soil type & & $*$ & & \\
PBDE application & & $* *$ & \\
ARE amendments & & & & \\
\hline
\end{tabular}

Asterisks denote significant difference between treatments

${ }^{*} p<0.05 ;{ }^{* *} p<0.01 ; * * * p<0.001$

${ }^{\mathrm{a}}$ By analysis of variance 
Fig. 3 Denaturing gradient gel electrophoresis (DGGE) separation of 16S rRNA genes in the red and black soils from different treatments. Specific bands in the red soils $(A 1-A 12)$ and black soils $(B 1-B 14) .1$ control, 2 glycine, 3 oxalic acid, and 4 fructose (in BDE-28-spiked soils); 5 control, 6 glycine, 7 oxalic acid, and 8 fructose (in BDE-47-spiked soils)

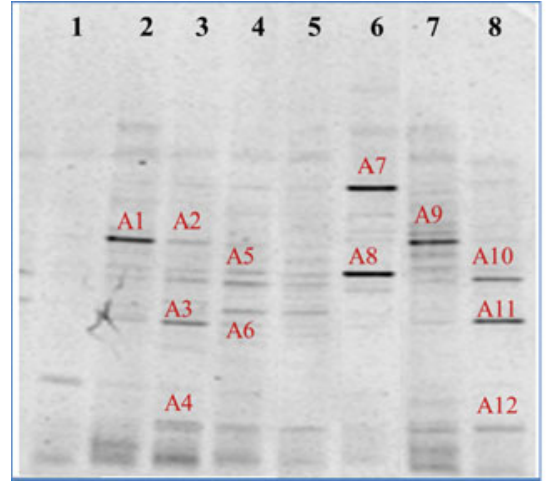

Red soil

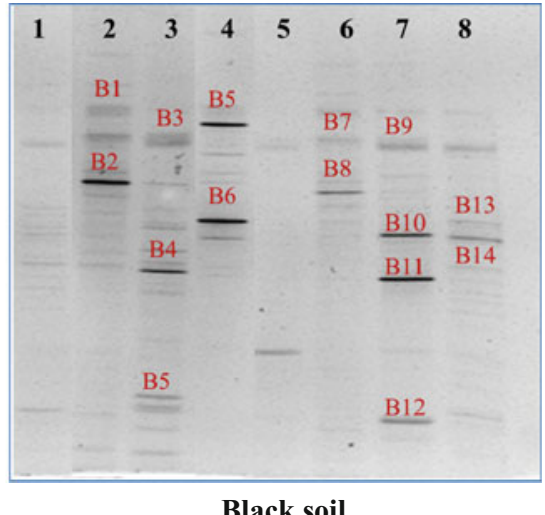

Black soil soils have the potential to promote the releases of organic matters complexed with soil minerals, resulting in the increase of DOC in soil solution (Yang et al. 2001). A remarkable increase in the concentration of soil DOC after the addition of root exudate components was also observed (Fig. S1). Furthermore, the contents of butanol-extractable BDE-28 and BDE-47 had a positive correlation with the concentration of soil DOC contents (Fig. 6). It was reported that root exudates increased DOC content in soil solution and were able to decrease the surface tension between organic contaminants and soil particles (Burken and Schnoor 1996), which leads to the dissolution of organic contaminants from soil matrices into the surrounding pore spaces. Wang et al. (2011) observed a strong tendency for PBDEs to complex with DOC and suggested a high affinity between PBDEs and DOC and DOCfacilitated dissolution of PBDEs from soils. Therefore, it is very likely that the enhanced availabilities of BDE-28 and BDE-47 in the soils are ascribed to the increased DOC content
Fig. 4 Degradation dynamics of BDE- 28 and BDE-47 in the red soils and black soils after application of root exudate components. The presented data are the mean of triplicates \pm standard errors. The data were fitted with the first-order kinetics equation

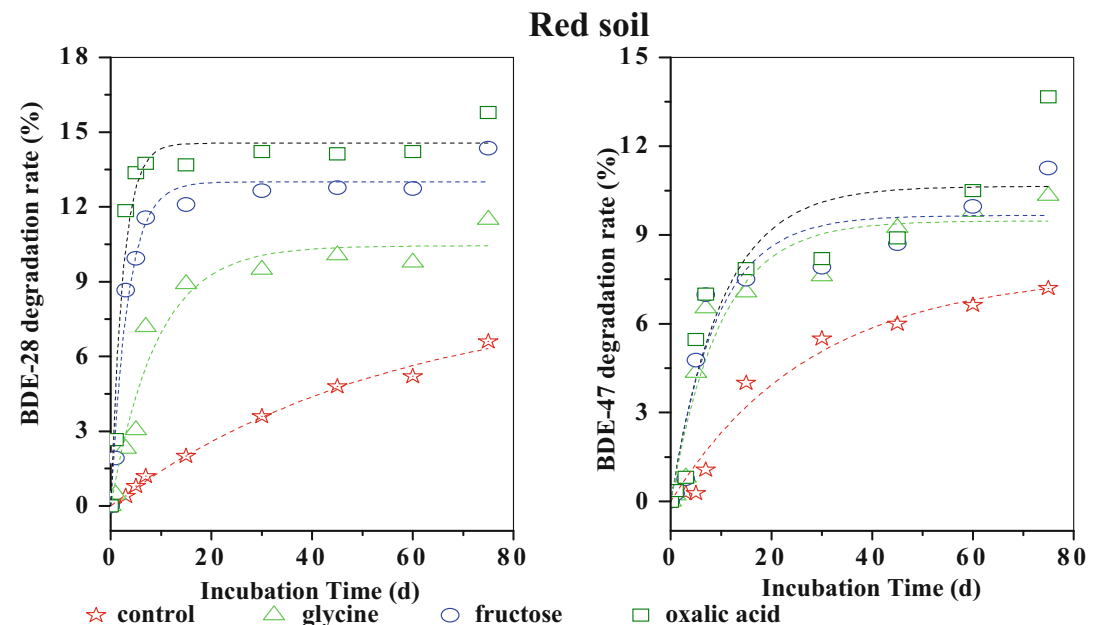

Black soil
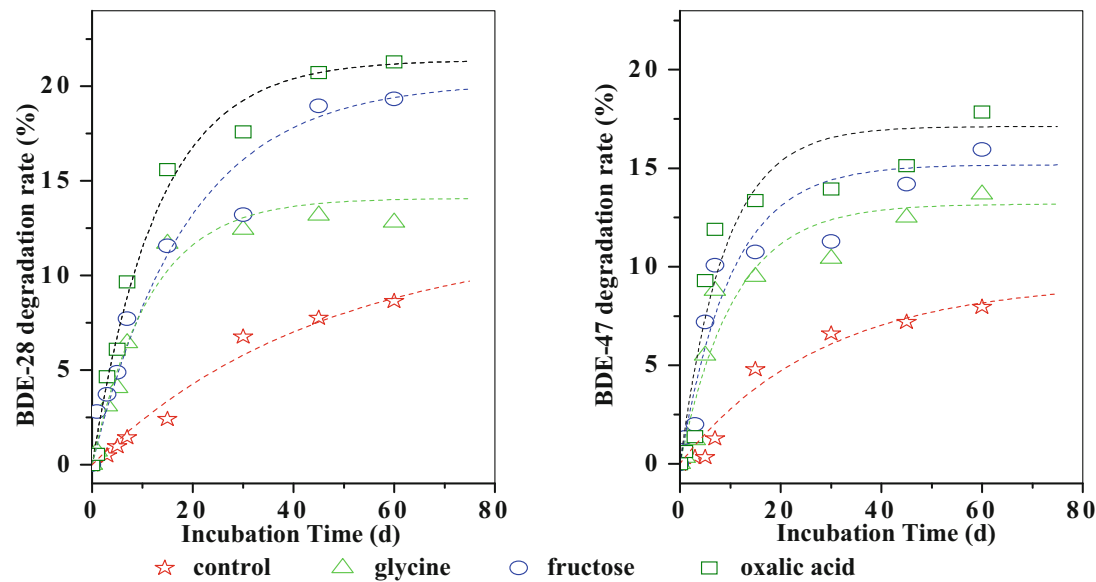
Fig. 5 Solubilities of BDE-28 and BDE-47 in the solutions of root exudate components with the concentrations ranging from 0 to $60 \mathrm{~g} / \mathrm{kg}$ and Milli-Q water used as a control. Error bars indicate the standard error of the mean $(n=3)$

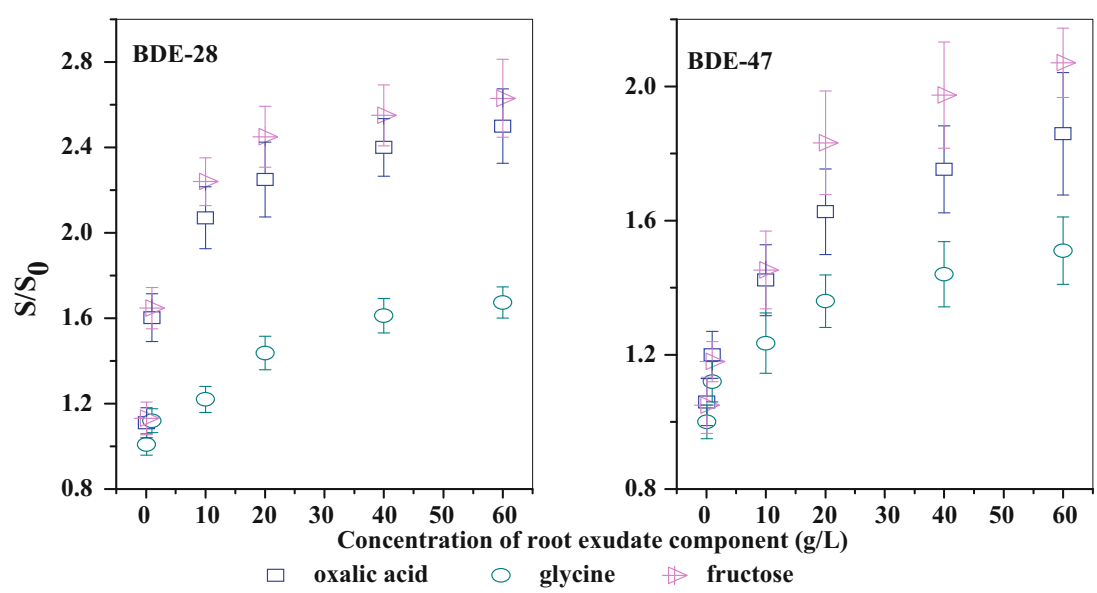

in the soils in the presence of root exudate components. Besides the change of DOM in soils, the addition of root exudate components may alter some physico-chemical properties of the soils such as functional group composition, surface polarity, and binding affinity of soil organic matter for organic contaminants. In addition, root exudate components containing carboxyl and hydroxyl groups can also affect the desorption of organic contaminants by competitive adsorption (Chiou et al. 2000), which can also facilitate the desorption of BDE-28 and BDE-47 from soils.

In this experiment, the soils were sealed in glass vials to minimize the losses of BDE-28 and BDE-47 via evaporation and photochemical degradation. Therefore, their dissipation was mainly due to biodegradation mediated by microbial processes. Biodegradation process, catalyzed by soil microbes, is governed by both abiotic and biotic factors (Boivin et al. 2005). There were several possible ways through which root exudate components enhanced the biodegradation of BDE-28 and BDE-47 in the soils. Interactions with root exudate components increased the water solubility and desorption of BDE28 and BDE-47 in the soils. Root exudate components enhanced the release of DOC to the soils, which further improved the bioavailability of BDE- 28 and BDE- 47 to the microorganisms. Thus, the increased desorption and availability of BDE-28 and BDE-47 as affected by root exudate components resulted in the enhancement of their biodegradation. Previous research has showed that root exudates can alter soil microbial biomass and composition of microbial communities as well as the function of these communities (Shi et al. 2011). We observed in this study that root exudate components significantly promoted soil microbial DNA content (Table 2). Furthermore, changes of microbial community were different as affected by different root exudate components (Fig. 3 and S2). We expected that the addition of root exudate components could impact both the structure and function of soil microbial community. Oxalic acid caused larger shifts of soil microbial community than did fructose and glycine. Furthermore, specific changes of microbial community composition were associated with specific root exudate components. For example, the addition of citric acid was found mainly to increase the microorganisms of Actinobacteria and Proteobacteria in soils (Eilers et al. 2010). However, detailed information about how root exudates affect the functional groups of soil microorganisms such as PBDE degraders and how this further influences biodegradation of PBDEs in soils remain unclear due to the limited resolution of DGGE analysis. Further research is thus necessary to identify the functional microbial group through target gene sequencing.

Desorption, extractability, and biodegradation were found different between BDE-28 and BDE-47 as well as among different root exudate components. BDE-47 with higher hydrophobicity and larger molecular size showed stronger affinity to soils and tended to have lower availability than did BDE-28. Compared with glycine and fructose, oxalic acid
Fig. 6 Positive correlation between the concentration of extractable PBDEs and DOC in the red soil and black soil
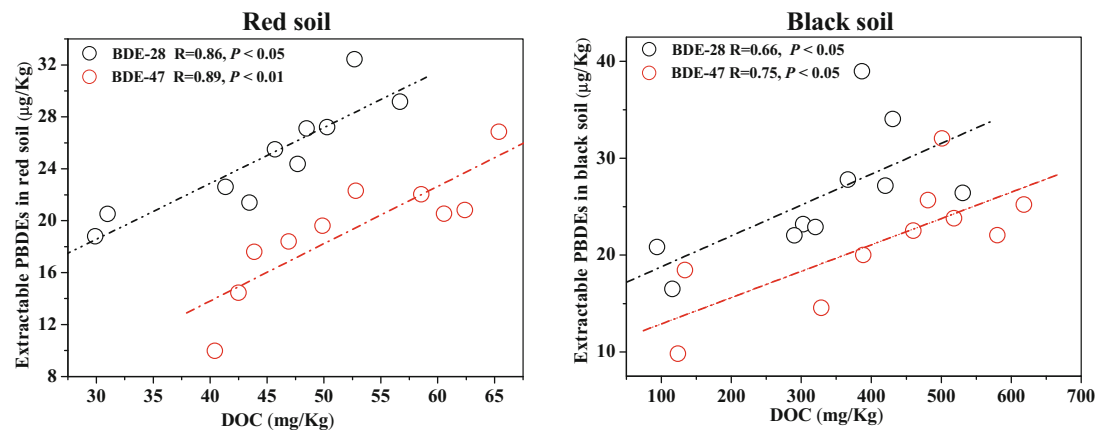
has smaller molecule volume with two carboxyl functional groups, which more easily dissolves metal cations and breaks the bridges between soil minerals and organic matter in mineral-organic matter complexes (Yang et al. 2001), therefore increasing DOC content in the soils more obviously (Fig. S5). As a result the addition of oxalic acid exerted a more important role than did glycine and fructose in enhancing the desorption and extractability of BDE- 28 or BDE-47 and promoting microorganism growth due to the increase of soil $\mathrm{C}$ resource. A greater impact of oxalic acid than fructose and glycine on soil bacterial communities has also been observed previously (Falchini et al. 2003).

\section{Conclusion}

Due to the interactions between root exudates, it is difficult to specify the effects of each individual root exudate component by using their mixture. This study examined and elucidated the effects of root exudate components on the desorption, availability, and biodegradation of BDE-28 and BDE-47 in soils. Oxalic acid was the most important one among root exudate components to increase the bioavailability and biodegradation of BDE-28 and BDE-47 in the soils. Enhanced water solubilities of BDE-28 and BDE-47, release of soil DOC, and stimulation of microbial growth are likely to be the key mechanisms responsible for root exudate components to promote the desorption, availability, and biodegradation of BDE-28 and BDE-47 in the soils. Further researches are necessary on the effects derived from real root exudates and comparison with the related effects of root exudate components on the behaviors of PBDEs in soils with the aim to comprehensively clarify the influence mechanisms of root exudate components on the behaviors of PBDEs in soils.

Acknowledgments This work was supported by the Strategic Priority Research Program of the Chinese Academy of Sciences (XDB14020202), the National Natural Science Foundation of China (Projects 21537005, 21177139), and Young Scientists Fund of RCEES (Project RCEES-QN-20130020F).

\section{References}

Bais HP, Weir TL, Perry LG, Gilroy S, Vivanco JM (2006) The role of root exudates in rhizosphere interactions with plants and other organisms. Annu Rev Plant Biol 57:233-266

Balseiro-Romero M, Kidd PS, Monterroso C (2014) Influence of plant root exudates on the mobility of fuel volatile compounds in contaminated soils. Int J Phytorem 16:824-839

Boivin A, Amellal S, Schiavon M, van Genuchten MT (2005) 2, 4Dichlorophenoxyacetic acid (2,4-D) sorption and degradation dynamics in three agricultural soils. Environ Pollut 138:92-99

Burken JG, Schnoor JL (1996) Phytoremediation: plant uptake of atrazine and the role of root exudates. J Environ Eng 122:958-963
Chiou CT, Kile DE, Rutherford DW, Sheng GY, Boyd S (2000) Sorption of selected organic compounds from water to a peat soil and its humic-acid and humin fractions: potential sources of the sorption nonlinearity. Environ Sci Technol 34:1254-1258

Corgié SC, Beguiristain T, Leyval C (2004) Spatial distribution of bacterial communities and phenanthrene (PHE) degradation in the rhizosphere of Lolium perenne. Appl Environ Microbiol 70:3552-3557

Corgié SC, Beguiristain T, Leyval C (2006) Differential composition of bacterial communities as influenced by phenanthrene and dibenzo[a, $\mathrm{h}$ ]anthracene in the rhizosphere of ryegrass (Lolium perenne L.). Biodegradation 17:511-521

Cui XY, Mayer P, Gan J (2013) Methods to assess bioavailability of hydrophobic organic contaminants: principles, operations, and limitations. Environ Pollut 172:223-234

Eilers KG, Lauber CL, Knight R, Fierer N (2010) Shifts in bacterial community structure associated with inputs of low molecular weight carbon compounds to soil. Soil Biol Biochem 42:896-903

Falchini L, Namova N, Kuikman PJ, Bloem J, Nannipieri P (2003) CO2 evolution and denaturing gradient gel electrophoresis profiles of bacterial communities in soil following addition of low molecular weight substrates to simulate root exudation. Soil Biol Biochem 35: 775-782

Farrar J, Hawes M, Jones D, Lindow S (2003) How roots control the flux of carbon to the rhizosphere. Ecology 84:827-837

Gao YZ, Ren LL, Ling WT, Gong SS, Sun BQ, Zhang Y (2010a) Desorption of phenanthrene and pyrene in soils by root exudates. Bioresour Technol 101:1159-1165

Gao YZ, Ren LL, Ling WT, Kang FX, Zhu XZ, Sun BQ (2010b) Effects of low-molecular-weight organic acids on sorption-desorption of phenanthrene in soils. Soil Sci Soc Am J 74:51-59

Hayat MT, Xu JM, Ding N, Mahmood T (2010) Dynamic behavior of persistent organic pollutants in soil and their interaction with organic matter. Molecular environmental soil science at the interfaces in the earth's critical zone. pp 217-222

He Y, Li XF, Shen XQ, Jiang Q, Chen J, Shi JC, Tang XJ, Xu JM (2015) Plant-assisted rhizoremediation of decabromodiphenyl ether for ewaste recycling area soil of Taizhou, China. Environ Sci Pollut Res 22:9976-9988

Huang HL, Zhang SZ, Christie P (2011) Plant uptake and dissipation of PBDEs in the soils of electronic waste recycling sites. Environ Pollut 159:238-243

Joner EJ, Corgié SC, Amellal N, Leyval C (2002) Nutritional constraints to degradation of polycyclic aromatic hydrocarbons in a simulated rhizosphere. Soil Biol Biochem 34:859-864

Kelsey JW, Kottler BD, Alexander M (1997) Selective chemical extract to predict bioavailability of soil-aged organic chemicals. Environ Sci Technol 31:214-217

Lee LK, He JZ (2010) Reductive debromination of polybrominated diphenyl ethers by anaerobic bacteria from soils and sediments. Appl Environ Microbiol 76:794-802

Li YF, Harner T, Liu L, Zhang Z, Ren MQ, Jia H, Ma J, Sverko E (2010) Polychlorinated biphenyls in global air and surface soil: distributions, air-soil exchange, and fractionation effect. Environ Sci Technol 44:2784-2790

Liste H, Alexander M (2002) Butanol extraction to predict bioavailability of PAHs in soil. Chemosphere 46:1011-1017

Luo L, Zhang SZ, Shan XQ, Zhu YG (2006) Oxalate and root exudates enhance the desorption of $p, p$-DDT from soils. Chemosphere 63: $1273-1279$

Martin BC, George SJ, Price CA, Ryan MH, Tibbett M (2014) The role of root exuded low molecular weight organic anions in facilitating petroleum hydrocarbon degradation: current knowledge and future directions. Sci Total Environ 472:642-653

Miya RK, Firestone MK (2001) Enhanced phenanthrene biodegradation in soil by slender oat root exudates and root debris. J Environ Qual 30:1911-1918 
Sellström U, de Wit CA, Lundgren N, Tysklind M (2005) Effect of sewage-sludge application on concentrations of higher-brominated diphenyl ethers in soils and earthworms. Environ Sci Technol 39: 9064-9070

Shi SJ, Richardson AE, O'Callaghan M, DeAngelis KM, Jones EE, Stewart A, Firestone MK, Condron LM (2011) Effects of selected root exudate components on soil bacterial communities. FEMS Microbiol Ecol 77:600-610

Semple KT, Morriss AWJ, Paton GI (2003) Bioavailability of hydrophobic organic contaminants in soils: fundamental concepts and techniques for analysis. Eur J Soil Sci 54:809-818

Sun BQ, Gao YZ, Liu J, Sun YD (2012) The impact of different root exudate components on phenanthrene availability in soil. Soil Sci Soc Am J 76:2041-2050

Tolls J (2001) Sorption of veterinary pharmaceuticals in soils: a review. Environ Sci Technol 35:3397-3406

Wang W, Delgado-Moreno L, Ye Q, Gan J (2011) Improved measurements of partition coefficients for polybrominated diphenyl ethers. Environ Sci Technol 45:1521-1527

Wang S, Zhang SZ, Huang HL, Niu ZC, Han W (2014) Characterization of polybrominateddiphenyl ethers (PBDEs) and hydroxylated and methoxylated PBDEs in soils and plants from an e-waste area. Environ Pollut 184:405-413
White JC, Mattina MI, Lee WY, Eitzer BD, Iannucci-Berger W (2003) Role of organic acids in enhancing the desorption and uptake of weathered $p, p$-DDE by Cucurbita pepo. Environ Pollut 124:71-80

White JC, Parrish ZD, Iseleyen M, Gent MPN, Iannucci-Berger W, Eitzer BD, Kelsey JW, Mattina MI (2006) Influence of citric acid amendments on the availability of weathered PCBs to plant and earthworm species. Int J Phytorem 8:63-79

Wong MH, Wu SC, Deng WJ, Yu XZ, Luo Q, Leung AO, Wong CS, Luksemburg WJ, Wong AS (2007) Export of toxic chemicals - a review of the case of uncontrolled electronic waste recycling. Environ Pollut 149:131-140

Wong F, Kurt-Karakus P, Bidleman TF (2012) Fate of brominated flame retardants and organochlorine pesticides in urban soil: volatility and degradation. Environ Sci Technol 46:2668-2674

Yang Y, Ratté D, Smets BF, Pignatello JJ, Grasso D (2001) Mobilization of soil organic matter by complexing agents and implications for polycyclic aromatic hydrocarbon desorption. Chemosphere 43: 1013-1021

Yoshitomi KJ, Shann JR (2001) Corn (Zea mays L.) root exudates and their impact on ${ }^{14} \mathrm{C}$-pyrene mineralization. Soil Biol Biochem 33: 1769-1776

Zhu YH, Zhang SZ, Huang HL, Wen B (2009) Effects of maize root exudates and organic acids on the desorption of phenanthrene from soils. J Environ Sci 21:920-926 